\title{
Outcomes of coronary artery bypass grafting and reduction annuloplasty for functional ischemic mitral regurgitation: A prospective multicenter study (Randomized Evaluation of a Surgical Treatment for Off-Pump Repair of the Mitral Valve)
}

\author{
Eugene A. Grossi, MD, ${ }^{\text {a }}$ Y. Joseph Woo, MD, ${ }^{b}$ Nirav Patel, MD, ${ }^{c}$ Judith D. Goldberg, ScD, ${ }^{\text {a }}$

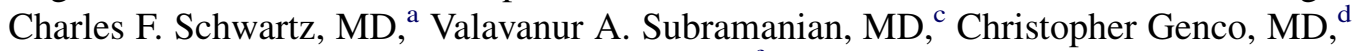 \\ Scott M. Goldman, MD, ${ }^{\mathrm{e}}$ Marco A. Zenati, MD, ${ }^{\mathrm{f}}$ J. Alan Wolfe, MD, ${ }^{\mathrm{g}}$ Yugal K. Mishra, MD, ${ }^{\mathrm{h}}$ and \\ Naresh Trehan, $\mathrm{MD}^{\mathrm{i}}$
}

Objective: Functional ischemic mitral regurgitation is a complication of ventricular remodeling; standard therapy is reduction annuloplasty and coronary artery bypass grafting. Unfortunately, outcomes are retrospective and contradictory. We report a multicenter study that documents the outcomes of reduction annuloplasty for functional ischemic mitral regurgitation.

Methods: Twenty-one centers randomized 75 patients to the coronary artery bypass grafting + reduction an-
nuloplasty subgroup that was the control arm of the Randomized Evaluation of a Surgical Treatment for Off-
pump Repair of the Mitral Valve trial. Entry criteria included patients requiring revascularization, patients
with severe or symptomatic moderate functional ischemic mitral regurgitation, an ejection fraction $25 \%$ or
greater, a left ventricular end-diastolic dimension $7.0 \mathrm{~cm}$ or less, and more than 30 days since acute myocardial
infarction. All echocardiograms were independently scored by a core laboratory. Reduction annuloplasty was
achieved by device annuloplasty. Two patients underwent immediate intraoperative conversion to a valve re-
placement because reduction annuloplasty was unable to correct mitral regurgitation; as-treated results are pre-
sented.

Results: Thirty-day mortality was $4.1 \%$ (3/73). Patients received an average of 2.8 bypass grafts. Mean followup was 24.6 months. Mitral regurgitation was reduced from $2.6 \pm 0.8$ preoperatively to $0.3 \pm 0.6$ at 2 years. Freedom from death or valve reoperation was $78 \% \pm 5 \%$ at 2 years. There was significant improvement in ejection fraction and New York Heart Association class with reduction of left ventricular end-diastolic dimension. Cox regression analyses suggested that increasing age $(P=.001$; hazard ratio, 1.16 per year; $95 \%$ confidence interval, $1.06-1.26)$ and renal disease $(P=.018$; hazard ratio, 3.48; $95 \%$ confidence interval, $1.25-9.72)$ were associated with decreased survival.

Conclusions: Coronary artery bypass grafting + reduction annuloplasty for functional ischemic mitral regurgitation predictably reduces mitral regurgitation and relieves symptoms. This treatment of moderate to severe mitral regurgitation is associated with improved indices of ventricular function, improved New York Heart Association class, and excellent freedom from recurrent mitral insufficiency. Although long-term prognosis remains guarded, this multicenter study delineates the intermediate-term benefits of such an approach. (J Thorac Cardiovasc Surg 2011;141:91-7)

\footnotetext{
From the New York University School of Medicine, ${ }^{a}$ New York, NY; Hospital of the University of Pennsylvania, ${ }^{b}$ Philadelphia, Pa; Lenox Hill Medical Center, ${ }^{c}$ New York, NY; Covenant Health Center, ${ }^{\mathrm{d}}$ Saginaw, Mich; Lankenau Hospital, ${ }^{\mathrm{e}}$ Lancaster, Pa; Veterans Administration Hospital, ${ }^{\mathrm{f}}$ Pittsburgh, Pa; St Joseph's Hospital, ${ }^{\mathrm{g}}$ Atlanta, Ga; Escorts Heart Institute and Research Centre, ${ }^{\mathrm{h}}$ New Delhi, India; and Indrapratha Apollo, ${ }^{i}$ New Delhi, India.

Disclosures: Authors have nothing to disclose with regard to commercial support.

Read at the 36th Annual Meeting of the Western Thoracic Surgical Association, Ojai, California, June 23-26, 2010.

Received for publication June 18, 2010; revisions received Aug 5, 2010; accepted for publication Aug 24, 2010.

Address for reprints: Eugene A. Grossi, MD, NYU Medical Center, Suite 9-V, 530 First Avenue, New York, NY 10016 (E-mail: Eugene.grossi@nyumc.org).

$0022-5223 / \$ 36.00$

Copyright (c) 2011 by The American Association for Thoracic Surgery

doi:10.1016/j.jtcvs.2010.08.057
}

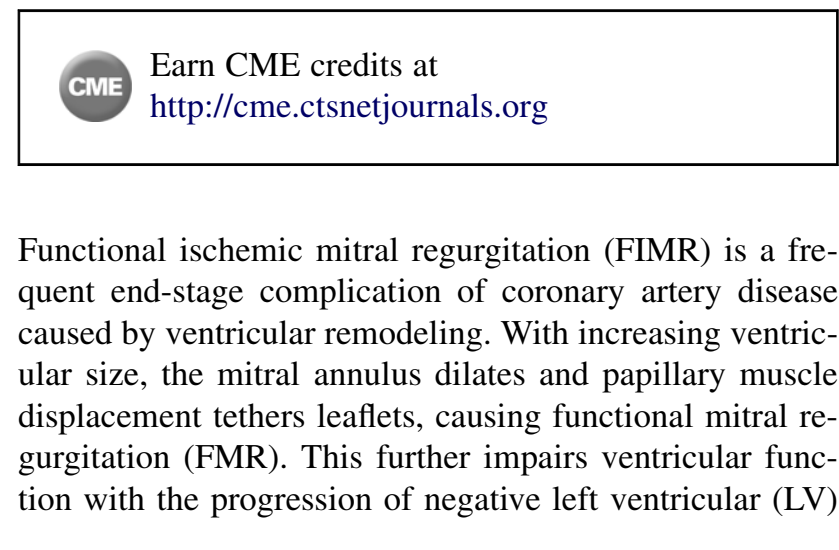

The Journal of Thoracic and Cardiovascular Surgery • Volume 141, Number 1 


$$
\begin{aligned}
& \text { Abbreviations and Acronyms } \\
& \text { CABG }=\text { coronary artery bypass grafting } \\
& \text { CI }=\text { confidence interval } \\
& \text { FDA }=\text { Food and Drug Administration } \\
& \text { FIMR }=\text { functional ischemic mitral regurgitation } \\
& \text { FMR }=\text { functional mitral regurgitation } \\
& \text { HR }=\text { hazard ratio } \\
& \text { LV }=\text { left ventricular } \\
& \text { LVED }=\text { left ventricular end diastolic } \\
& \text { MR }=\text { mitral regurgitation } \\
& \text { RA }=\text { reduction annuloplasty }
\end{aligned}
$$

remodeling. ${ }^{1,2}$ Current treatments for LV dysfunction with FMR include medical therapy and surgery. With viable ischemic myocardium, revascularization prevents further damage, relieves the contributing ischemia, and may stop or reverse the remodeling process. The effect of correcting the ischemia alone on valve function has been unpredictable and often transient, leaving the majority of patients with residual, recurrent, or progressive mitral regurgitation (MR). ${ }^{3}$ Significant MR is treated by valve repair or replacement. Mitral repair is primarily done with a reduction annuloplasty (RA), whereby an undersized annuloplasty device increases the coaptive leaflet margin and eliminates regurgitation. ${ }^{4}$ Current surgical techniques for FMR have significant procedural risk, and the late outcomes remain guarded. ${ }^{5}$ Although valve repair is generally believed to be superior to replacement, replacement is sometimes recommended in patients with significant leaflet tethering who are considered high risk for recurrence. ${ }^{6}$

Thus, the gold standard therapy for FIMR is RA and coronary artery bypass grafting (CABG) when appropriate. Outcome data are retrospective, limited to individual series, and somewhat contradictory. This report details a prospective, multicenter, independently monitored and audited study that documents the outcomes of RA for FIMR using core laboratory reviewed data.

\section{MATERIALS AND METHODS}

Twenty-one centers (Appendix 1) randomized 75 patients to a $\mathrm{CABG}+\mathrm{RA}$ as a stratum in the control arm of the Randomized Evaluation of a Surgical Treatment for Off-pump Repair of the Mitral Valve trial. This Food and Drug Administration (FDA)-approved investigational device trial (Clinical Trials ID $=$ NCT00120276) compared CABG plus ventricular reshaping (Coapsys; Myocor Inc, Maple Grove, Minn) with $\mathrm{CABG}+\mathrm{RA}$; the primary, comparative outcomes have been reported. ${ }^{7} \mathrm{~Pa}-$ tients were on average 65.8 years old and predominately male $(86.3 \%)$. Table 1 contains patient demographic information for the 75 randomized patients. The FDA's study entry criteria favored the exclusion of particularly high-risk surgical candidates to evaluate differences in midterm survival. Entry criteria included patients requiring revascularization, patients with severe FIMR (or symptomatic moderate FIMR), an ejection fraction $25 \%$ or greater, an LV end-diastolic (LVED) dimension $7.0 \mathrm{~cm}$ or less, and more than 30 days since an acute transmural myocardial infarction. Appendix 2 shows full inclusion/exclusion criteria. All echocardiograms were independently reviewed and scored by a core laboratory (Mayo Clinic). MR severity was graded as $0=$ none, $1=$ mild, $2=$ moderate, $3=$ moderate-severe, and $4=$ severe. RA was achieved by band or ring annuloplasty; the type of annuloplasty device was chosen at the surgeon's discretion. Two patients underwent intraoperative conversion to chordal sparing mitral valve replacement due to an inability to correct MR with RA. The as-treated results are presented.

This study was approved by each participating medical center's institutional review board. Adverse events were adjudicated by an independent Clinical Events Committee, and results were monitored by a Data Safety Monitoring Board. The trial was initiated as a feasibility study in April 2003 and expanded with FDA approval into a pivotal study in June 2004. This study was prematurely terminated when the sponsor failed to secure ongoing funding in October 2008. At the time of closure, 165 patients had been randomized. Mean follow-up was 24.6 months. The database was maintained in Clindex (FORTRESS Medical Systems, Hopkins, $\mathrm{MN}$ ), and statistical analyses, such as mixed model and multivariable Cox regression, were performed using SAS (SAS Institute Inc, Cary, NC) and SPSS (SPSS Inc, Chicago, IL). Mean and standard deviations are reported.

\section{RESULTS}

Operative mortality was $4.1 \%$ (3/73). Patients received a mean of 2.8 bypass grafts. Multivariable Cox regression analyses revealed that older age $(P=.001$; hazard ratio $[\mathrm{HR}]=1.16 / \mathrm{y} ; 95 \%$ confidence interval $[\mathrm{CI}], 1.06-1.26)$ and the presence of renal disease $(P=.018 ; \mathrm{HR}=3.48$; $95 \%$ CI, 1.25-9.72) were associated with decreased survival. Renal disease $(P=.007 ; \mathrm{HR}=3.8 ; 95 \% \mathrm{CI}, 1.5-10.0)$, older age $(P=.055$; HR $=1.1,95 \% \mathrm{CI}, 0.99-1.1)$, and LV endsystolic volume index $(P=.091, \mathrm{HR}=1.02,95 \% \mathrm{CI}$, $0.99-1.04)$ were associated with decreased freedom from death, reoperation, or recurrent MR (moderate or worse).

MR severity was significantly reduced from $2.54 \pm 0.80$ at baseline to $0.52 \pm 0.66$ and $0.35 \pm 0.63$ at 1 and 2 years, respectively (Table 2). Two patients had RA performed without impact on MR grade and had to be intraoperatively converted to mitral replacement; these patients were excluded from this as-treated analysis. In total, 12 patients $(16.1 \%)$ had moderate or worse recurrent MR during follow-up. The technical details of these patients are included in Appendix 3.

Five patients had moderate MR at discharge and a $48 \%$ 2-year survival; however, this was not statistically significant when compared with all patients $(P=.45)$. One patient had recurrent MR (mild at discharge and moderate-severe at 1 year) with reoperative valve replacement at 15 months. This patient's baseline LVED dimension was $6.3 \mathrm{~cm}$ with a baseline ejection fraction of $40 \%$.

Table 3 summarizes the functional and dimensional changes. Ejection fraction significantly improved from $38 \%$ to $47 \%$ at 2 years. Reverse remodeling was evident with significant decreases in end-diastolic and endsystolic dimensions. New York Heart Association class significantly improved in the majority of patients; $65.9 \%$ improved 1 or more grades at 1 year and $72.0 \%$ at 2 years. 
TABLE 1. Demographics and disease characteristics in the 75 patients randomized to bypass and reduction annuloplasty

\begin{tabular}{|c|c|c|c|}
\hline & Mean/no. & Range & $\mathrm{N}$ missing \\
\hline Age (y) & $65.6 \pm 8.7$ & & \\
\hline $\operatorname{LVEF}(\%)$ & $38.3 \pm 10.3$ & & \\
\hline Weight (kg) & $82.2 \pm 19.8$ & & \\
\hline $\operatorname{MR}(0-4)^{*}$ & $2.86 \pm 0.7$ & & \\
\hline No. grafts & $2.76 \pm 1.0$ & $1-6$ & \\
\hline Male gender & $63(84 \%)$ & & $1.4 \%$ \\
\hline \multicolumn{4}{|l|}{ NYHA class } \\
\hline I & $5(6.7 \%)$ & & $4.0 \%$ \\
\hline II & $31(41.3 \%)$ & & \\
\hline III & $36(48.0 \%)$ & & \\
\hline IV & $0(0 \%)$ & & \\
\hline \multicolumn{4}{|l|}{ No. of grafts performed } \\
\hline 1 & $8(10.7 \%)$ & & $1.3 \%$ \\
\hline 2 & $18(24.0 \%)$ & & \\
\hline 3 & $35(46.7 \%)$ & & \\
\hline 4 & $11(14.7 \%)$ & & \\
\hline 5 & $1(1.3 \%)$ & & \\
\hline 6 & $1(1.3 \%)$ & & \\
\hline Diabetes & $42(56 \%)$ & & $2.7 \%$ \\
\hline Renal insufficiency & $20(26.7 \%)$ & & $1.3 \%$ \\
\hline \multicolumn{4}{|l|}{ Smoking } \\
\hline Current & $20(26.7 \%)$ & & $1.3 \%$ \\
\hline Previous & $34(45.3 \%)$ & & \\
\hline Non & $20(26.7 \%)$ & & \\
\hline PVD & $16(21.3 \%)$ & & $5.3 \%$ \\
\hline History of CHF & $48(64.0 \%)$ & & $2.7 \%$ \\
\hline \multicolumn{4}{|l|}{ History of MI } \\
\hline Anterior & $10(13.3 \%)$ & & $1.3 \%$ \\
\hline Inferior & $24(32.0 \%)$ & & \\
\hline Lateral & $5(6.7 \%)$ & & \\
\hline History of stroke & $6(8.0 \%)$ & & $5.3 \%$ \\
\hline Prior CABG & $0(0 \%)$ & & $2.7 \%$ \\
\hline History of PCI & $11(14.7 \%)$ & & $2.7 \%$ \\
\hline History of atrial fibrillation & $20(26.7 \%)$ & & $10.7 \%$ \\
\hline History of ICD & $1(1.3 \%)$ & & $1.3 \%$ \\
\hline
\end{tabular}

LVEF, Left ventricular ejection fraction; $M R$, mitral regurgitation; $N Y H A$, New York Heart Association; $P V D$, peripheral vascular disease; $C H F$, congestive heart failure; $M I$, myocardial infarction; $C A B G$, coronary artery bypass grafting; $P C I$, percutaneous coronary intervention; $I C D$, implantable cardioverter defibrillator. Continuous variables are presented as mean \pm standard deviation. *MR grades: $0=$ none, $1=$ mild, $2=$ moderate, $3=$ moderate-severe, $4=$ severe

Occurrences of adverse events post-randomization are shown in Table 4.

A variety of annuloplasty devices from different manufacturers were used, ranging in size from $24 \mathrm{~mm}$ to $30 \mathrm{~mm}$ (mean, $27 \mathrm{~mm}$ ). Some $20.6 \%$ of the devices were soft and not rigid or semi-rigid. Neither annuloplasty device type (rigid/soft or complete/band) nor size affected recurrent MR alone or the combined end point of freedom from death, valve reoperation, or recurrent MR. Late systolic mitral valve tenting area and diastolic annular area were analyzed along with the aforementioned factors; only mitral valve tenting area was weakly associated with any reoccurrence of $\operatorname{MR}(P=.18)$.
TABLE 2. Echocardiography core laboratory distribution of mitral insufficiency grades in $\mathbf{7 0}$ patients* treated by coronary artery bypass grafting and mitral repair

\begin{tabular}{lcccrr}
\hline & Baseline N & Predischarge & $\mathbf{1 ~ y}$ & $\mathbf{1 . 5} \mathbf{y}$ & $\mathbf{2 ~ y}$ \\
\hline None & 0 & 41 & 25 & 19 & 19 \\
Mild & 5 & 11 & 19 & 12 & 5 \\
Moderate & 31 & 5 & 1 & 2 & 2 \\
Moderate-severe & 25 & 0 & 1 & 0 & 0 \\
Severe & 9 & 0 & 0 & 0 & 0 \\
\hline *Missing 3 baseline evaluations & & & &
\end{tabular}

\section{DISCUSSION}

This study provides benchmark outcomes data for the surgical strategy of CABG + RA for coronary artery disease and FMR. The short-term mortality of $4.1 \%$ is better than that reported by the Society of Thoracic Surgeons and others, but we have enlisted a "non-high-risk" patient cohort as dictated by the trial design with ejection fraction, age, LVED dimension, and non-emergency surgery restrictions. The midterm results, however, are nearly identical to what has been reported. Recent publications on CABG and mitral repair for FMR indicate that mortality rates are similar to those of the $\mathrm{CABG}+$ mitral valve repair stratum of the Randomized Evaluation of a Surgical Treatment for Offpump Repair of the Mitral Valve, with a weighted 1-year mortality rate of $19 \%{ }^{1,5,8-13}$ It is important to note that these data represent the first prospective, multicenter evaluation of surgical treatment of FMR. Significant rigor was applied in this study, including a data safety monitoring board, independent event adjudication by the clinical events committee, and core laboratory analyses of all echocardiography indices. The rigor of our audited follow-up makes our dataset robust.

Because this was a multicenter study, surgeon variability was a factor in how the procedure was performed. As noted, a wide variety of different annuloplasty devices was used and performance was not distinguishable, perhaps because of the small number of each device type used or perhaps there is no difference among the repair devices! In the last few years, greater precision of leaflet coaptation measurement has been obtained with 3-dimensional echocardiography. ${ }^{14}$ With this improved granularity in our echocardiographic studies of FMR, we will be better able to predict which patients are at risk for recurrent MR.

A question prompted by this study was "How and when do we grade MR?" Although the echocardiography laboratory has precise criteria for measurements, there are other methodological issues. FMR is variable by nature according to patient loading conditions. Varying baseline conditions were accommodated by accepting the baseline transthoracic echocardiogram within 1 month of the surgery. Several other phenomena were also observed. Eccentric jets that were not appreciated on preoperative transthoracic echocardiography were occasionally noted on the 
TABLE 3. Echocardiography core laboratory analysis in 73 patients treated by coronary artery bypass grafting and mitral repair

\begin{tabular}{lcccc}
\hline & Baseline & $\mathbf{1 ~ y}$ & $\mathbf{1 . 5} \mathbf{y}$ & $\mathbf{2} \mathbf{y}$ \\
\hline MR grade & $2.54 \pm 0.81(\mathrm{~N}=70)$ & $0.52 \pm 0.66^{*}(\mathrm{~N}=46)$ & $0.35 \pm 0.63^{*}(\mathrm{~N}=33)$ & $0.48 \pm 0.62 *(\mathrm{~N}=26)$ \\
LVEF & $37.9 \pm 11.7(\mathrm{~N}=67)$ & $47.0 \pm 12.5 \dagger(\mathrm{N}=46)$ & $46.5 \pm 11.8 \dagger(\mathrm{N}=33)$ & $47.0 \pm 12.9 \ddagger(\mathrm{N}=25)$ \\
LVED $(\mathrm{cm})$ & $5.83 \pm 0.68(\mathrm{~N}=60)$ & $5.34 \pm 0.86 \dagger(\mathrm{N}=38)$ & $5.55 \pm 0.80(\mathrm{~N}=26)$ & $5.16 \pm 0.75 \ddagger(\mathrm{N}=17)$ \\
LVES $(\mathrm{cm})$ & $4.66 \pm 0.89(\mathrm{~N}=57)$ & $3.94 \pm 1.08 \dagger(\mathrm{N}=35)$ & $4.26 \pm 1.03(\mathrm{~N}=23)$ & $3.96 \pm 0.95 \ddagger(\mathrm{N}=17)$ \\
\hline
\end{tabular}

$M R$, Mitral regurgitation; $L V E F$, left ventricular ejection fraction; $L V E D$, left ventricular end diastolic; $L V E S$, left ventricular end systolic. Mixed model, pairwise comparison versus baseline, adjusted for multiple comparisons. ${ }^{*} P<.001 . \dagger P=.001 . \ddagger P=.01$

intraoperative transesophageal echocardiography study. Additionally, as previously reported, ${ }^{3}$ the degree of intraoperative MR was often downgraded compared with the baseline study. Accurate numeric quantification was difficult because many of the current methods of assessing MR, such as proximal isovelocity surface area, are based on assumptions applicable to structural disease, but not to the broad jet origins and multiple jets present in functional disease.

It is important to note that this study documented a recurrence of moderate MR in $16 \%$ of the patients with a mean follow-up of 2 years. This is significantly lower than the percentage suggested by others. ${ }^{12}$ We could speculate that this difference is related to the rigor applied to selecting patients with pure functional MR and "reasonable" ventricular sizes, and the avoidance of recent transmural myocardial infarctions. ${ }^{15}$

This study demonstrates the difficulty in recruiting patients for such a surgical study. The surgeon (not being a gatekeeper) was typically called in to see a catheterization film (and patient) the day before a requested surgery. There was rarely an echocardiogram done before the catheterization. This presented a logistic nightmare to screen the patient, obtain an echocardiogram for the core laboratory to review, and arrange for trial personnel to be available. Such issues are being encountered in patient recruitment with the current National Institutes of Health Cardiac Research Network trials.

\section{Limitations}

Core laboratory analysis failed to retrospectively confirm at least moderate MR on a few baseline transthoracic echocardiograms because of incomplete views. These patients had confirmed moderate MR on intraoperative transesophageal echocardiography. The study was designed in 2002 and 2003 and did not capture all the data of interest that we would want to capture today, such as serial B-type natri-

TABLE 4. Occurrences of primary adverse events during follow-up

\begin{tabular}{lc}
\hline \multicolumn{1}{c}{ PAE event } & $\mathbf{N}=\mathbf{7 3}$ \\
\hline Death & $18(24.7 \%)$ \\
Stroke & $5(6.8 \%)$ \\
Myocardial infarction & $5(6.8 \%)$ \\
All cardiac reoperation & $4(5.5 \%)$ \\
Reoperation for repair dysfunction & $1(1.6 \%)$ \\
\hline
\end{tabular}

PAE, Pulmonary air embolism. uretic peptide levels and baseline cardiac magnetic resonance imaging scans. As noted in the Discussion section, the individual surgeon chose the annuloplasty device and sizing strategy for RA; mandating such was beyond the scope of this trial. In addition, the low number of significant MR recurrences limits the statistical capability to identify any suboptimal repair techniques.

\section{CONCLUSIONS}

CABG + RA for FIMR predictably reduces MR and relieves symptoms. This operative strategy for the treatment of moderate to severe MR is associated with improved indices of ventricular geometry, improved New York Heart Association functional class, and excellent freedom from recurrent mitral insufficiency. Although long-term prognosis remains guarded, this multicenter study delineates the intermediate benefits of such an approach. This study sets a benchmark for the design and execution of a study pertaining to surgically treated FMR.

\section{References}

1. Trichon BH, Glower DD, Shaw LK, Cabell CH, Anstrom KJ, Felker GM, et al. Survival after coronary revascularization, with and without mitral valve surgery, in patients with ischemic mitral regurgitation. Circulation. 2003;108(Suppl 1): II103-10.

2. Komeda M, Glasson JR, Bolger AF, Daughters GT 2nd, MacIsaac A, Oesterle SN, et al. Geometric determinants of ischemic mitral regurgitation. Circulation. 1997;96(9 Suppl):II-128-33.

3. Aklog L, Filsoufi F, Flores KQ, Chen RH, Cohn LH, Nathan NS, et al. Does coronary artery bypass grafting alone correct moderate ischemic mitral regurgitation? Circulation. 2001;104(12 Suppl. 1):I68-75.

4. Bax JJ, Braun J, Somer ST, Klautz R, Holman ER, Versteegh MI, et al. Restrictive annuloplasty and coronary revascularization in ischemic mitral regurgitation results in reverse left ventricular remodeling. Circulation. 2004;110(11 Suppl. 1):II103-8.

5. Grossi EA, Bizekis CS, LaPietra A, Derivaux CC, Galloway AC, Ribakove GH, et al. Late results of isolated mitral annuloplasty for "functional" ischemic mitral insufficiency. J Card Surg. 2001;16:328-32.

6. Calafiore AM, Gallina S, Di Mauro M, Gaeta F, Iaco AL, D'Alessandro S, et al. Mitral valve procedure in dilated cardiomyopathy: repair or replacement? Ann Thorac Surg. 2001;71:1146-53.

7. Grossi EA, Patel N, Woo YJ, Goldberg JD, Schwartz CF, Subramanian V, et al. Outcomes of the Randomized Evaluation of a Surgical Treatment for Off-pump Repair of the Mitral Valve (RESTOR-MV) Trial. J Am Coll Cardiol. 2010;24:56.

8. Gillinov AM, Blackstone EH, Rajeswaran J, Mawad M, McCarthy PM, Sabik JF 3rd, et al. Ischemic versus degenerative mitral regurgitation: does etiology affect survival? Ann Thorac Surg. 2005;80:811-9.

9. Serri K, Bouchard D, Demers P, Coutu M, Pellerin M, Carrier M, et al. Is a good perioperative echocardiographic result predictive of durability in ischemic mitral valve repair? J Thorac Cardiovasc Surg. 2006;131:565-73. e2.

10. Wong DR, Agnihotri AK, Hung JW, Vlahakes GJ, Akins CW, Hilgenberg AD, et al. Long-term survival after surgical revascularization for moderate ischemic mitral regurgitation. Ann Thorac Surg. 2005;80:570-7. 
11. Glower DD, Tuttle RH, Shaw LK, Orozco RE, Rankin JS. Patient survival characteristics after routine mitral valve repair for ischemic mitral regurgitation. J Thorac Cardiovasc Surg. 2005;129:860-8.

12. McGee EC, Gillinov AM, Blackstone EH, Rajeswaran J, Cohen G, Najam F, et al. Recurrent mitral regurgitation after annuloplasty for functional ischemic mitral regurgitation. J Thorac Cardiovasc Surg. 2004;128:916-24.

13. Kim YH, Czer LS, Soukiasian HJ, De Robertis M, Magliato KE, Blanche C, et al. Ischemic mitral regurgitation: revascularization alone versus revascularization and mitral valve repair. Ann Thorac Surg. 2005;79:1895-901.

14. Gogoladze G, Dellis SL, Donnino R, Ribakove G, Greenhouse DG, Galloway A, et al. Analysis of the mitral coaptation zone in normal and functional regurgitant valves. Ann Thorac Surg. 2010;89:1158-61.

15. Braun J, van de Veire NR, Klautz RJ, Versteegh MI, Holman ER, Westenberg JJ, et al. Restrictive mitral annuloplasty cures ischemic mitral regurgitation and heart failure. Ann Thorac Surg. 2008;85:430-7.

\section{Discussion}

Dr Vince Gaudiani (Redwood City, Calif). This article shows that some of our best surgical groups can achieve excellent palliation in medium-risk patients with ischemic MR using coronary bypass and annuloplasty ring.

Ischemic MR occurs because the mitral annulus is dilated and the posterior LV wall and chordal apparatus do not function correctly. A ring can reduce the size of the annulus but it cannot untether the chordal apparatus. As a profession, we spend a substantial amount of effort devising rings to reduce annular size but less time trying to understand how the posterior wall contributes to mitral valve function. There are 3 factors that alone or in any combination can delay or reduce the forward motion of the mitral subvalve apparatus: posterior wall ischemia that could conceivably be improved by bypassing, posterior wall fibrosis as the result of infarction, or delayed electrical activation from right ventricular apex pacing or left bundle branch block. If the posterior wall is ischemic, CABG and ring annuloplasty will be effec- tive, and I imagine that most of these 75 patients whose condition improved had just that problem. If there is posterior wall fibrosis from infarction or frank aneurysmal change, the situation will be different. Finally, there is abundant evidence that right ventricular apex pacing and left bundle branch block double the risk of heart failure requiring hospitalization at every level of $\mathrm{LV}$ function. Therefore, we must begin to look at electrocardiograms as carefully as we look at echocardiograms. Biventricular pacing is an important adjunct to $\mathrm{CABG}$ and annuloplasty in these patients with increased LV size and prolonged $\mathrm{QR}$ restoration. It is also important to point out that LV inferior wall removal and restructuring plus or minus mitral valve replacement is effective in patients who have large dead inferior walls, but because we discuss this topic as if ischemic MR were one entity rather than the group of entities I just described, I think we frequently miss the point.

Did the 2 patients who required mitral valve replacement have dead inferior walls, and how many of these patients had left bundle branch block or were paced from the right ventricular apex?

Dr Grossi. I can give you a bit of information about activation times, and this is an observation. We have not dug this out, but patients who were treated with ventricular reshaping postoperatively had narrower QRS complexes. We do not know what that truly means. It was associated with differences in survival, but we really don't know whether it was due to a difference in activation times. What I can tell you is that approximately two thirds of these patients had inferior wall function, either akinesia or paradoxing motion (subnormal motion). Of these patients, approximately $25 \%$ improved in terms of their inferior wall function as seen on segmental echocardiogram analysis. Approximately $15 \%$ had worsening of their inferior walls. 
APPENDIX 1. Randomized Evaluation of a Surgical Treatment for Off-Pump Repair of the Mitral Valve investigational sites

\begin{tabular}{|c|c|}
\hline Site & PI \\
\hline Aspirus Wausau Hospital (Wis) & Fernando Riveron \\
\hline Baystate Medical Center (Mass) & John Rousou \\
\hline $\begin{array}{l}\text { Covenant Healthcare Medical } \\
\text { Center (Mich) }\end{array}$ & Norbert Baumgartner \\
\hline Duke University (NC) & R. Duane Davis \\
\hline Emory University (Ga) & Thomas Vassiliades \\
\hline Enloe Medical Center (Calif) & Li Poa \\
\hline $\begin{array}{l}\text { Escorts Heart Institute and } \\
\text { Research Centre (India) }\end{array}$ & Yugal Mishra \\
\hline Geisinger Health System $(\mathrm{Pa})$ & Alfred Casale \\
\hline $\begin{array}{l}\text { Hospital of the University of } \\
\text { Pennsylvania }(\mathrm{Pa})\end{array}$ & Y. Joseph Woo \\
\hline Indraprastha Apollo & Naresh Trehan/Sanjay Mittal \\
\hline Lankenau Hospital (Pa) & Francis Sutter/Scott Goldman \\
\hline Lenox Hill Hospital (NY) & Valvanur Subramanian/Nirav Patel \\
\hline $\begin{array}{l}\text { Nebraska Heart Institute Lincoln } \\
\quad(\mathrm{Neb})\end{array}$ & James Wudel \\
\hline $\begin{array}{l}\text { Nebraska Heart Institute Omaha } \\
\text { (Neb) }\end{array}$ & Deepak Gangahar \\
\hline $\begin{array}{l}\text { New York University Hospital - } \\
\text { Tisch (NY) }\end{array}$ & Eugene Grossi \\
\hline $\begin{array}{l}\text { New York University Medical } \\
\text { Center - VA (NY) }\end{array}$ & Eugene Grossi \\
\hline $\begin{array}{l}\text { Northwest Surgical Associates/ } \\
\text { Legacy (Ore) }\end{array}$ & Thomas Malloy \\
\hline $\begin{array}{l}\text { Prairie Education and Research } \\
\text { Cooperative (Ill) }\end{array}$ & Carl Arentzen \\
\hline Rhode Island Hospital (RI) & Arun Singh \\
\hline Spectrum Health (Mich) & Charles Willekes \\
\hline St Joseph Mercy Hospital (Mich) & Benjamin McCallister \\
\hline St Joseph’s (Md) & Kimble Jett/John Laschinger \\
\hline $\begin{array}{l}\text { St Josephs Hospital and Medical } \\
\text { Center (Ariz) }\end{array}$ & Michael Caskey \\
\hline St Joseph's Hospital of Atlanta (Ga) & J. Allan Wolfe \\
\hline St Luke’s Hospital (Pa) & Terrence Theman \\
\hline St Luke’s (Wis) & David Kress \\
\hline $\begin{array}{l}\text { Stony Brook University Hospital } \\
\text { (NY) }\end{array}$ & Thomas Bilfinger/Todd Rosengart \\
\hline $\begin{array}{l}\text { The Cleveland Clinic Foundation } \\
\text { (Ohio) }\end{array}$ & Tomislav Mihaljevic \\
\hline $\begin{array}{l}\text { VA Pittsburgh Healthcare System } \\
(\mathrm{Pa})\end{array}$ & Marco Zenati \\
\hline
\end{tabular}




\section{APPENDIX 2. Study inclusion/exclusion criteria}

These criteria were selected by the sponsor in collaboration with the FDA. The philosophy of the study design was to (1) select patients with pure functional MR in whom there was enough disease to warrant valvular intervention and (2) select patients whose comorbidities would be associated with sufficient survival to allow assessment of device therapy.

Inclusion criteria (patients were included if they met all of the following criteria):

1. Grade 2, 3, or 4 functional mitral valve regurgitation per 2-dimensional echocardiography. For the purpose of this study, functional mitral valve regurgitation is defined as mitral valve dysfunction caused by dilation of the mitral valve annulus, displacement of the LV papillary muscles, chordal tethering of the mitral valve leaflets, or any combination of these characteristics. This was core laboratory verified.

2. Patient undergoing concomitant coronary artery bypass graft surgery, either on-pump or off-pump (CABG or OP-CAB).

3. LV ejection fraction $>25 \%$ per 2-dimensional echocardiography.

4. Age between 18 and 80 years, inclusive.

5. Patient willing and available to return for study follow-up.

6. Ability of the patient or legal representative to understand and provide signed consent for participating in the study.

Exclusion criteria (patients were excluded from study participation if they met any of the following criteria):
1. Structural abnormality of the mitral valve (eg, calcification or thickening of valve leaflets, ruptured papillary muscle, ruptured chordae tendinea, mitral valve prolapse, mitral stenosis)

2. Organic valve disease resulting in insufficiency or stenosis of the aortic, pulmonary or tricuspid valve requiring surgical intervention

3. Transmural myocardial infarction within 30-day period before surgical placement of Coapsys (Myocor Inc, Maple Grove, Minn)

4. NYHA class IV

5. LVED diameter $>7.0 \mathrm{~cm}$

6. Cardiac surgery on an emergency or salvage basis

7. Left atrial or LV thrombus

8. LV aneurysm

9. Previous mitral valve surgery or other previous cardiac surgery that would preclude proper placement of the Coapsys

10. Chronic renal failure requiring dialysis

11. Open chest surgery contraindication (eg, acute respiratory distress, endocarditis, myocarditis, pericarditis)

12. Active infection

13. Life expectancy of $<12$ mo

14. Participation in another investigational drug or device protocol

$F D A$, Food and Drug Administration; $M R$, mitral regurgitation; $O P-C A B$, off-pump coronary artery bypass; $C A B G$, coronary artery bypass grafting; $L V$, left ventricular; NYHA, New York Heart Association; $L V E D$, left ventricular end diastolic.
APPENDIX 3. Details of patients with recurrent mitral insufficiency $(\mathbf{n}=12)$

\begin{tabular}{ll}
\hline \multicolumn{1}{c}{ Mean ejection fraction } & \multicolumn{1}{c}{$\mathbf{3 7 . 4} \%$} \\
\hline Mean LVEDD $(\mathrm{cm})$ & $6.1 \mathrm{~cm}$ \\
Soft annuloplasty device used & $1(8.3 \%)$ \\
Annuloplasty device $>28 \mathrm{~mm}$ & $7(58.3 \%)$ \\
\hline
\end{tabular}

